\title{
Autoradiographic Image
}

National Cancer Institute

\section{Source}

National Cancer Institute. Autoradiographic Image. NCI Thesaurus. Code C95161.

The image from a photographic or sensor plate used in a autoradiography process. 